\title{
M
}

a journal of the Society for Music Theory

Volume 18, Number 2, June 2012

Copyright (C) 2012 Society for Music Theory

\section{Scriabin and the Possible}

\section{Anna M. Gawboy and Justin Townsend}

NOTE: The examples for the (text-only) PDF version of this item are available online at: http://www.mtosmt.org/issues/mto.12.18.2/mto.12.18.2.gawboy_townsend.php

KEYWORDS: Scriabin, Prometheus, op. 60, tastiera per luce, musical multimedia, performance and analysis

ABSTRACT: Alexander Scriabin imagined his Prometheus: Poem of Fire, op. 60, as a spectacular "dual symphony" of light and sound. For much of the work's history, however, the light part remained enigmatic and technologically unperformable, contributing to a vicious cycle between performance and analysis. An incomplete understanding of the function of the lights resulted in a disregard for Scriabin's lighting notation in performances, while the unavailability of accurate, convincing performances has inhibited curiosity regarding the lights' full analytical potential.

This paper reassesses the relationship between music and lights in Prometheus, drawing upon new research regarding the nature of Scriabin's vision. We explore the potential of the lights to perform a real-time visual analysis of the music using video excerpts from our 2010 performance with the Yale Symphony Orchestra.

Received February 2012

[1] Multimedia performances of Alexander Scriabin's music have become increasingly common in recent years. $\left.{ }^{*}\right)$ Often, the paratexts surrounding these productions invoke Scriabin's synesthetic sensibility and his decision to include a part for colored lights in his Prometheus, Poem of Fire, op. 60, presumably to justify the use of multimedia on historic grounds. But rarely, if at all, do light shows adhere to Scriabin's color-music system or accurately realize the part for lights he wrote for Prometheus. (1) Consequently, the performance practice embeds a curious double-standard: while musicians strive to interpret what is written, designers frequently disregard Scriabin's indications in favor of adding their own visuals.

[2] This practice parallels the performance of opera, where the visual elements (such as costumes, lighting, and staging) are created fresh for each new production, while the music is interpreted from surviving notation. However, the relationship between music and lights in Prometheus is very different from the relationship between music and lights in a musical drama. Prometheus was to be an entirely new genre: a "symphony of sound" counterpointed by a "symphony of light" (Sabaneev 2000 [1925], 99).

[3] Scriabin notated the part for colored lights using pitches on a musical staff, and later supplemented this with a detailed 
written description. Together, these sources communicate a visual display of symphonic proportions. The use of musical notation allowed Scriabin to achieve an unprecedented level of precision regarding the coordination of colors, durations, lighting dynamics, special effects, and musical events. At the same time, it has raised questions regarding the relative status of music and lights within the work as a whole. According to Nicholas Cook, Scriabin's use of musical symbols "subordinates colour to musical principles" (1998, 37), but one could just as easily imagine that Scriabin's notational specificity for both was an attempt to equalize the status of music and color. In other words, Scriabin's detailed lighting score transforms an element typically regarded as incidental into an essential part of the conceptual whole.

[4] This article explores the implications of the latter perspective for both the analysis and performance of Prometheus. Part I outlines how the work's fraught performance history and the enigmatic nature of the light part have contributed to current attitudes and practices. Parts II and III describe Scriabin's system of tone-color correspondence and how the lights relate to the music. We consider the potential of the lights to perform a real-time visual analysis, revealing and clarifying aspects of Prometheus's obscure musical structure. Part IV considers additional musical functions of the light part, and how these functions may be concealed or emphasized in performance. In this section, we draw upon our own experience producing a lighted realization of Prometheus.

\section{Part I: The imaginary part for colored lights}

[5] Scriabin premiered and published Prometheus in 1911, but those events were just two points on a longer timeline of the work's conceptual evolution. Scriabin began writing and talking about Prometheus around 1908, a time when his plans for the Mysterium were already beginning to crystalize. Both projects would involve the coordinated stimulation of multiple senses. While Scriabin contemplated ways to arouse all five senses in the Mysterium, he conceived Prometheus as a more limited experiment focused on the interaction between sight and sound (Schloezer 1987 [1923], 254-58).

[6] In the months leading up to the Moscow premiere, Scriabin worked with the technician Alexander Mozer to create a tastiera per luce (also known as clavier à lumières), an electric color keyboard they hoped could equal the power of the orchestra. A version of this instrument, pictured in Example 1, is on display at the Scriabin State Museum in Moscow. Scriabin's private experiments with the luce left favorable impressions with his friend and biographer Leonid Sabaneev, but Scriabin ultimately decided to withdraw the instrument from the public premiere due to unspecified "technical difficulties" (Sabaneev 1974 [1912], 131). Prometheus entered the orchestral repertory as an ordinary unlit tone poem, and so it remained for much of its performance history.

[7] When the orchestral score was published in 1911, it contained only a simple part for luce written in musical notation, presumably for Mozer's primitive instrument. Oddly, the first edition contained no further instructions for the lights, not even a guide to translate Scriabin's musical notation into colors. Although individuals close to Scriabin disseminated various color tables for Prometheus, the color assignments in these secondary sources sometimes conflicted. (2) And while Scriabin imagined that the lights would brighten and dim according to the mood of the music (Sabaneev 1974 [1912], 131), there were no dynamic indications for luce in the published score, possibly because Mozer's instrument was not capable of varying its intensity.

[8] We now have greater insight into the considerable distance between Scriabin's ambitions for the lights and the disappointment of his early twentieth-century technological reality. In 1913, two years after the failed premiere, Scriabin made copious notes for luce in a first-edition score of Prometheus. This document, known as the Parisian score, contains the only table of color-tone correspondences known to come directly from the composer. Scriabin's other annotations indicate a level of spectacle far beyond the capacity of Mozer's luce. He calls for dynamic changes of light intensity and fantastic special effects such as tongues of flame, lighting, fireworks, and sparks. The precise coordination of music and effects indicated by the Parisian score would have been impossible to achieve in 1913. (3) The annotations, then, are traces of the luce part as it existed in Scriabin's imagination, freed from the practical limitations of an actual performance. They provide a tantalizing glimpse into Scriabin's creative aims and possess rich interpretive potential.

[9] The Parisian score manuscript provides a wealth of information unavailable in published versions of Prometheus, but 
designers today only rarely use it to inform their realizations. $\left.{ }^{4}\right)$ For much of the twentieth century, it was unavailable for study. The Sabaneev estate held the score privately until 1978, the year it was archived at the Bibliothèque Nationale in Paris. (5) There is still no published edition, and the manuscript's existence has not been widely publicized.

[10] As a result, misconceptions about Prometheus still persist, despite the Parisian score's reappearance. The long absence of reliable primary literature about Prometheus has generated a cottage industry of misleading secondary information, some of which has been reified as common knowledge in the Internet age. (6) Furthermore, while the Parisian score has yielded new insights into the luce's colors, dynamics, and effects, there is still confusion about the origin of the notated light part and its relationship to the music.

[11] One of the most widespread myths about Prometheus is that the luce part had something to do with Scriabin's alleged synesthesia. Today, we think of synesthesia as an involuntary neurological condition (Cytowic 2002), but it is important to recognize that over the past century, the definition of synesthesia has narrowed. One hundred years ago, "synesthesia" could refer to a broad range of cross-sensory phenomena, regardless of whether such mappings arose through neurological, psychological, pathological, artistic, intellectual, spiritual, or mystic means (Dann 1998). These changing definitions have led to controversy over the nature of Scriabin's colored hearing. (7) While the majority of the concert-going public now assume Scriabin's synesthesia was neurological in origin, Sabaneev indicated that Scriabin deliberately constructed his system of tone-color correspondence for its artistic and spiritual effects (Sabaneev 1929, 267n1). It is perhaps most accurate to say that Scriabin was a synesthete according to the way the phenomenon was framed during his own time period, but according to current definitions he was not.

[12] The myth of the neurological origin of Scriabin's synesthesia has had unfortunate consequences in both performance practice and scholarship. In performance, this myth (combined with the primitive notation for luce in the published score) has resulted in a tradition that presents the luce as a shifting play of colors, without nuance or other effects. In scholarship, this myth has contributed to a lack of curiosity regarding the full extent of Scriabin's color-correspondence system. Just as the Parisian score revealed the luce part in Prometheus to be far more than color alone, Scriabin's carefully worked-out scheme turns out to be far more analytically interesting than the spontaneous mappings typical of neurological synesthetes.

[13] Example 2 presents a page from the orchestral score with Scriabin's Parisian annotations translated in the upper margin. The part for luce, notated on the top staff, consists of two separate lines of color. Stems up indicate a more quickly changing sequence, and stems down mark a slower part that sustains a single color through longer sections of music. In measures 15-25 the faster voice moves among pitches drawn from the minor third cycle F\#-A-C-Eb, while the slower voice holds F\#. (8)

[14] "The colour underlines the tonality," Scriabin told the British psychologist Charles Myers in 1915, "it makes the tonality more evident" (Myers 1914-15, 113). While it has been known for a long time that the faster-moving pitches relate to the harmonic rhythm, the music-analytical potential of the luce has not been fully investigated. Furthermore, the relationship of the slower-moving part to the fast part or to the unfolding musical drama has remained largely a matter of speculation. The next two sections outline Scriabin's system of tonality-color correspondence and explore the potential of the lights to perform a visual analysis of the work, clarifying aspects of musical structure in real time.

\section{Part II: The fast Ilunce and harmonic distance}

[15] Before the release of the Parisian score in 1978, the best information about Scriabin's system of tone-color correspondence came from Sabaneev's account, published in the Moscow journal Musyka two months before the 1911 premiere. Example 3 compares Sabaneev's tone-color mappings (1911a, 199) with Scriabin's “Table of Colors" found in the Parisian score. The differences between the two are fairly minor, consisting of subtle variations of hue. For example, Ab is

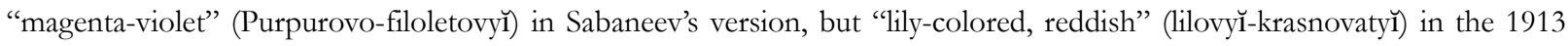
Parisian score. In a later article, Sabaneev described how Scriabin devised his system:

I know that originally he recognized clearly no more than three colors—red, yellow, and blue, corresponding 
to $\mathrm{C}, \mathrm{D}$, and F-sharp respectively. The others he deduced rationally, as it were, starting from the assumption that related keys correspond to related colors; that in the realm of color the closest relationship coincides with proximity in the spectrum; and that as regards tonalities it is connected with the circle of fifths. (Sabaneev 1929, 273)

[16] Sabaneev not only emphasized the deliberate, constructed nature of Scriabin's tone-color system, but he also revealed its basic underlying premise. Adjacent colors on the spectrum are correlated with closely-related tonalities on the circle of fifths, each represented by a "keynote" (or fundamental). Because there are twelve keynotes and only six or seven named spectral hues, Scriabin expanded his palette of colors by stretching red and blue over several key areas and adding non-spectral colors such as "steely-blue" and "metallic leaden grey."

[17] Scriabin's analogy between spectral close-relation and musical close relation appears logical when the colors stand for keynotes and their associated major scales, as some of Sabaneev's writings imply (Sabaneev 1929). Some modern editions of Prometheus, such as those of Dover and Eulenberg, add the diagram shown in Example 4 to the score in an effort to make the luce part more accessible (Scriabin 1995 and n.d. [ca. 1980]). Although now the "Musico-Chromo-Logo Schema" often appears without attribution, it was constructed by Irina Vanechkina and Bulat Galeev in 1975, prior to the reappearance of the Parisian score (Vanechkina 1975, 33).

[18] The Schema correlates major key signatures on the circle of fifths with color designations and evocative descriptions. A comparison with Example 3 shows that the color assignments more or less follow Sabaneev's table, but Galeev and Vanechkina add the warmer hues of "flesh" and "rose" to the metallic colors associated with $\mathrm{Eb}$ and $\mathrm{Bb}$. However, there is a larger issue with Galeev and Vanechkina's Schema, one that compromises its ability to serve as a guide to the relationship between the luce part and the music of Prometheus: Scriabin did not compose Prometheus using major keys.

[19] According to Sabaneev (Sabaneev 1974 [1912], 134), Scriabin constructed Prometheus entirely from transpositions of the mystic chord. Each color in the luce represents the fundamental of the mystic chord when its pitches are arranged in stacked fourths-the collection's original normalized form (Example 5). (9) An analysis of the score reveals that pitches in the luce part do indeed correspond to the mystic fundamental with remarkable consistency. (10) The faster-moving luce part, then, is Scriabin's fundamental-bass analysis of his own music.

[20] Sabaneev's claim that Prometheus was based entirely on transpositions of the mystic chord became increasingly unfashionable in western scholarship after the rise of other forms of collectional analysis. For example, both Baker (1986) and Cheong (1990) called the mystic chord's referential status into question to clear the way for their own methodological perspectives (set theory and octatonicism, respectively). While it is true that Scriabin worked with various collections in his piano works, opp. 61-74, the mystic chord is the most important structural sonority in Prometheus.

[21] Consider the opening twelve measures, reduced in Example 6. The total pitch content of the passage is $\{F \mathbb{\#}, \mathrm{G}, \mathrm{A}, \mathrm{B} b$, $\mathrm{B}, \mathrm{C} \mathbb{\#}, \mathrm{D} \mathbb{\#}\}$ which can be expressed as the integers $\{6,7,9,10,11,1,3\}$. James Baker's strict set theory perspective forced him to interpret all pitches as collectional tones (1986, 236). He considered the mystic set class 6-34 [013579] to be operational until measure 10, where the fleeting eighth-note entrance of $\mathrm{Bb}$ converts the collection into the slightly more chromatic set class 7-26 [0134579].

[22] Example 7 juxtaposes Baker's analysis of measures 9-12 with the perspectives of two other analysts. Pople suggests that the opening mystic chord, presented by the orchestra as a shimmering tremolando simultaneity, governs all of measures 1-12. His analysis treats the $\mathrm{Bb}$ in measure 10 as a collectional outsider, behaving very much like an escape tone (1989, 222). Taruskin also admits the presence of non-collectional tones, but his octatonic reading leads him to interpret the $\mathrm{B}^{\mathrm{h}}$ on the downbeat of measure 10 as an appoggiatura and the $B b$ as its resolution (2005, 218-19). (11) This alternative transforms the mystic chord into another sonority preferred by Scriabin, the octatonic subset 6-Z49 [013479].

[23] So, is the collection in the tenth measure of Prometheus set class 7-26, 6-34, or 6-Z49? Without any other contextual information, any one of the three interpretations is arguably possible. As Reise (1983) and Taruskin (1988, 1997) have 
pointed out, segmentation and set identification are notoriously problematic in Scriabin's late music. There are no universallyaccepted criteria to establish segmentation boundaries or to distinguish between "collectional" and "embellishing" tones. As a result, the analytical discussion can stall at the stage of merely identifying sets. This is particularly the case in the late piano works, as the debate over the harmonic basis of Scriabin's Prelude, op. 67 no. 1 illustrates. (12)

[24] However, we do have a key to the collections Scriabin used to construct Prometheus. The luce part operates as an analytical guide to the musical surface, indicating the mystic chord transposition governing each passage. In Example 6, the luce part sustains F\# (dark-blue violet) and A (green) through all twelve measures. The function of the luce's sustained F\# will be discussed in the next section of this paper, but the A corresponds to the fundamental of the A mystic chord when it is

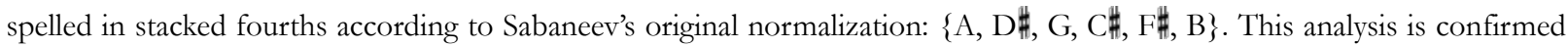
by the fact that all pitches in the score correspond orthographically to this spelling of the mystic chord, except for the $\mathrm{B} b$ escape tone Pople identifies in measure 10.

[25] The luce part provides a reliable means to track progressions of the mystic chord based on root motion. Example 8 shows a reduction of measures 13-21, the passage immediately following that given in Example 6. While one voice in the luce continues to sustain an F\#, the mobile voice moves to pitches related on a minor third cycle: Eb, C, A, and F\#.

[26] Our modern analytical habit in non-tonal music of translating pitch classes into integer notation can obscure these important aspects of Scriabin's usage. The mystic chord's orthography is critical in determining segmentation boundaries, as illustrated by the colored zones in Example 8. (13) Within each zone, pitches in the score correspond orthographically to the

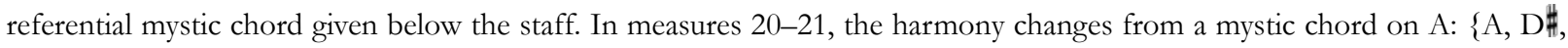
$G, C \#, F \#, B\}$, to a mystic chord on $E b$ : $\{E b, A, D b, G, C, F\}$. These two chords, related by T6, share four out of six pitch classes: $\mathrm{C} \# / \mathrm{Db}, \mathrm{D} \# / \mathrm{Eb}, \mathrm{G}$, and A. While integer notation efficiently reveals the proximity of these chords in terms of pitch class invariance, the shifts from $C \#$ to $\mathrm{Db}$ and from $\mathrm{D} \#$ to $\mathrm{Eb}$ indicate precisely where the harmony changes.

[27] As Pople noted, describing the mystic chord as a member of set class 6-34 [013579] involves a host of theoretical implications that do not quite match up with Scriabin's usage (1989, 24-25, 216-17). This representation deemphasizes the chord's root and orthographic distinctions under transposition. As a result, the relationship between the music of Prometheus, its referential scale-set, and luce part became unnecessarily opaque. (14) Furthermore, set class 6-34 includes not only a

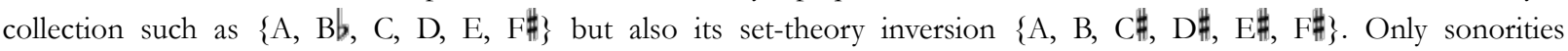
corresponding to the former form of 6-34 appear in Prometheus, making the set-theory notion of inversional equivalence irrelevant within the compositional language of the piece. Indeed, transposition is the prime operator here, moving mystic chords through Scriabin's color-coded gamut.

[28] Sabaneev (1929, 273) insisted that Scriabin's system of tonality-color correspondence had something to do with harmonic distance, an aspect of Scriabin's late style that merits further analytical investigation. As we have seen, Scriabin's analogy between spectrally adjacent (or "close" colors) with closely-related tonalities on the circle of fifths works when the "tonality" in question is a major scale. Prometheus was Scriabin's first large-scale composition in which he systematically avoided the use of major/minor tonality. Why, then, is it also the only work he actually scored for colored lights?

[29] In our view, the color-tonality of Prometheus rests on a three-way analogy between spectral colors, mystic collections, and major keys on the circle of fifths. As a heuristic tool, the circle of fifths relates tonal distance directly to spatial distance on the circle itself. Major keys that are maximally invariant from one another (i.e., sharing at least six out of seven pitch classes) are located on adjacent stations, and keys that are the most remote (sharing only one enharmonically-equivalent pitch class) are placed in diametric opposition across the circle from one another.

[30] Scriabin's substitution of mystic collections for major keys in Prometheus distorts this neat classical correlation of tonal and spatial distance in interesting ways. On the mystic circle of fifths, illustrated in Example 9, the closest possible transpositional relationship holds four out of six pitch classes invariant, a relationship obtainable at T2, T4, T6, T8, and T10. (On Example 9, T2 and T10 are collapsed into transpositional class 2, and T4 and T8 are collapsed into transpositional class 4 for ease of navigation.) Any given mystic chord has five closely related chords located at symmetrically spaced non-adjacent 
positions on the wheel.

[31] Why would Scriabin place his mystic chords on the circle of fifths when such an arrangement is meaningless for tonal distance defined through pitch-class invariance? Transposition of the mystic chord up or down a fifth preserves only two of the six pitch classes, which is neither the most distant nor the closest invariance-relation.

[32] Scriabin's arrangement is not based on pitch-class invariance, but rather the distinctive orthographies of transposed mystic chords. Each mystic chord in Example 10 has an orthography loosely corresponding to the major scale based on the same keynote, where the point of correspondence is the number and type of accidentals in each collection. For example, $\mathrm{G}$ major and $G$ mystic both have one sharp, D major and D mystic both have two sharps, and A major and A mystic both have three sharps. Like F major, F mystic has one flat; like Bb major, Bb mystic has two flats. Of course, the specific accidentals in the mystic collections are different from those in the parallel major scale.

[33] This general principle holds for all but mystic chords rooted on C (1 flat, 1 sharp), B (4 sharps), and Eb (2 flats). These exceptions, however, powerfully demonstrate the correlation between color and orthography that lies at the heart of Scriabin's system. Both E and B mystic have four sharps, but they also share a color word, "light blue” [golubol] in Scriabin's "Table of Colors" in the Parisian score. Similarly, Bb and Eb mystic have two flats, and Scriabin described them both as "metallic" colors. Sabaneev's 1911 article reinforced these pairings by listing the color of B as merely "similar to" E, and the color of Bb as "similar to" Eb (Sabaneev 1911a, 1999).

[34] The spatial location of mystic chords on the wheel is a guide to Scriabin's conception of tonal distance based on root relationships and orthography. Example 10 shows how tonal distance is measured in the number of fifth transpositions separating one chordal root from another. One fifth-transposition along the wheel separates $\mathrm{C}$ mystic and its closest clockwise neighbor, G, while six fifth-transpositions separate $\mathrm{C}$ and its most distant relation of F\#. The "close-relationship" of adjacent mystic chords is supported by orthography, in that the number of accidentals varies minimally. A move by one fifth-transposition adds or subtracts a single accidental from the total, while there is no change in the number of accidentals between $\mathrm{E}$ and $\mathrm{B}$ or $\mathrm{Eb}$ and $\mathrm{Bb}$. (15)

[35] This alternative means of understanding tonal distance in Prometheus can complement traditional conceptions of tonal distance based on pitch-class invariance. In Example 11, a reduction of measures 72-78, the harmony oscillates between mystic chords on the blue-violet F\# and red C. In terms of root motion and orthography, F\# and C mystic are the furthest removed from one another, located at diametrically opposed positions on the circle-of-fifths. However, in terms of pitch-class invariance, T6 preserves four of six pitch classes, making the oscillation between $\mathrm{C}$ and F\# remarkably hard to hear. Scriabin composed the solo piano's left-hand figuration entirely from the pitch classes shared by the two mystic chords $[F \#, C / B \#, E$, and $A \# / B b]$, further obscuring the shifts between collections. Scriabin could have clarified the harmonic rhythm by consistently placing the root of the mystic chord in the bass, but he does not.

[36] It is possible that a highly skilled listener could learn to detect the subtle shifts between the variant pitch classes D-D\# and $A-G \mathbb{Z}$, particularly when they are juxtaposed in the piano's right hand in measures 73-75. An analyst looking over the score could determine where the collection changes through the changes of pitch and respellings of $\mathrm{Bb} / \mathrm{A \#}$ and $\mathrm{C} / \mathrm{B} \#$. But these clues would likely be lost on most listener-viewers of Prometheus. In a performance, the luce part would make the harmonic rhythm obvious through the radical color changes between blue-violet and red.

[37] Cook points out that, without proper initiation, the luce's colors will appear arbitrary to most viewers of Prometheus (1998, 40). But it has long been acknowledged that the existence of an organizational system in music does not necessarily translate into perceptual transparency. (16) Scriabin's choices of pitch might seem just as arbitrary as his colors, although both arose from a highly-structured compositional method.

[38] Cook argues that the lights are subordinate to the music not only because they appear arbitrary, but also because of the way the colors depend on the mystic chord fundamentals. The luce part "duplicates the musical information through a direct translation to another medium, without adding any additional information of its own" $(1998,38)$. This characterization of 
the luce rests on an assumption that the music is structurally unambiguous, but analytical disagreements over the collectional basis and segmentation of Prometheus suggest otherwise.

[39] Scriabin apparently prided himself on devising a sonority that was aurally inscrutable, especially when a tone other than the root sounded in the bass. During one of Sabaneev's visits to Scriabin, the composer played the mystic chord on the piano and asked his friend to identify its pitches. Scriabin took delight in Sabaneev's inability to do so (Sabaneev 2000 [1925], 50). Scriabin evidently believed that the music of Prometheus was resistant to aural analysis, and that the colors could act as a guide to the harmonic changes. Had Scriabin initiated Sabaneev into his system of tonality-color correspondence prior to their aural skills game, a color cue could have allowed Sabaneev to identify the root of the mystic chord and then extrapolate the remaining pitches.

[40] This is perhaps what Scriabin was getting at in his comment to Myers that the colors "[make] the tonality more evident." Given the music's aural opacity, the lights perform an interpretive function by delineating the harmonic rhythm.

[41] But Mozer's 1910 luce was more than just a sequence of changing colors; rather, it incorporated the idea of tonal distance and symmetrical partitions into its very design. If the colors of the twelve lights corresponded to the twelve colors on Scriabin's circle of fifths, the luce would not only measure harmonic distance through color contrasts but also trace out specific fundamental bass patterns on its circular face. In other words, Scriabin's original luce functioned as a musictheoretical "space" animated with light and color.

[42] Scriabin's habit of structuring his fundamental bass motions according to equal divisions of the octave suggests that he composed Prometheus with the visual symmetries of the luce in his mind's eye. Video 1 presents an animation of what this might look like, using an excerpt from Prometheus beginning at measure 67. The harmony begins on an F\# mystic chord, then proceeds quickly through a minor third cycle, creating a symmetrical four-fold division of the luce's circular face. In measures 70-78, harmonies oscillate between F\# and C mystic, as we saw in Example 11. Although these latter shifts in harmony are nearly impossible to hear, the luce manifests their diametric opposition by activating lights that are literally across from one another on the circle.

[43] The conflict between what is seen and heard in measures 70-78 reveals one of the fundamental aspects of Scriabin's late style. Scriabin chose pitch structures that are highly invariant under tritone transposition, allowing him to bend musical space like a Mobius strip. F\# and C mystic chords are at once the most proximate harmonies in terms of pitch-class invariance, yet they are the most distant in terms of root relations. In Video 1, the aural impression of harmonic homogeneity is contradicted by the visual representation of the actual root distance. Together, information gleaned from the two senses combines to form a contradictory composite that reveals the paradoxical essence of Scriabin's late harmonic practice.

\section{Part III: The slow lluuce, form, and narrative}

[44] Although it has been known for a long time that the faster-moving luce voice relates to the harmonic motion of the music, the function of the slow luce part has remained largely a matter of speculation. Initially, it appears to have little relationship to the music or to the mystic chord harmonies. Example 12 provides an overview of the seven large-scale color changes in the slow luce part. These color changes are notated as a whole-tone scale beginning and ending on F\#, or dark blue-violet. (17)

[45] Pople proposes that the pitches of the slow luce form a deep background scale, a kind of non-tonal Ursatz. While he finds it possible to imagine the foreground harmonies in measures 1-86 "prolonging" F\#," he acknowledges that "seen reductively, the 'choice' of pc 6 in this instance seems arbitrary" (Pople 1989, 246). Cook, echoing Gleich (1963, 71) and MacDonald $(1978,56)$, declares that the slow luce "has no readily discernible relationship to the musical structure (1998, 38)." The large-scale musical structure of Prometheus, however, has not been particularly well-understood.

[46] Most analysts have viewed the work's trajectory in terms of the formal conceits of symphonic sonata form. Certainly, Prometheus exhibits elements of sonata form, but Scriabin obscures the work's large-scale formal boundaries through a near-constant use of thematic transformation and limited use of literal repetition, which is mostly confined to the local 
level. (18) Example 13 compares large-scale formal segmentations proposed by Gleich (1963), Delson (1971), Baker (1986), and Horst-Lederer (1980). The lack of consensus over major turning points in the form suggests that the analytical criteria for distinguishing between structural and non-structural events in Prometheus do not easily fall out from the music itself.

[47] Even for points of relative concordance in Example 13, a deeper investigation reveals oddities that are difficult to explain away. For example, the analysts agree that the recapitulation begins in the vicinity of measures 370-75. The return of the piano's virtuoso entrance from measure 31 to 45 triggers a strong sense of formal articulation, although the passage is transposed down a major third from its original appearance. Yet, locating the beginning of the recapitulation around measure 370 fails to account for the important return of material marked "avec émotion et ravissement [with emotion and rapture]" nearly sixty measures earlier. The rapture episode, which first appeared in measures 115-30, returns transposed up a major third in measures 309-26. Perhaps the piano's entrance is a more salient formal marker than the rapture music beginning at measure 309, but in both cases the promise of large-scale formal return is denied as the music charts a new course through substantial sections of new material and transformations of previously-heard music.

[48] These difficulties suggest that even when a point of formal articulation is relatively clear, fitting the musical events of Prometheus into a coherent narrative based on sonata-form rhetoric is a bit of a stretch. Pople goes so far as to avoid the sonata paradigm entirely in his analysis, preferring to view the work as concatenation of interrelated smaller-scale events $(1989,215)$. Given the ambiguity of the formal design, the slow luce part has the potential to perform an interpretive function by imposing a high-level grouping scheme upon the unruly texture. The slowly-changing background colors provide stability for each section on the large scale, visually unifying the thematic diversity of the musical surface. In a way, then, the slow luce freed Scriabin from the demands of tightly-knit formal architectonics, allowing him greater flexibility in thematic alteration and the introduction of new material.

[49] Furthermore, as even Gleich admits $(1963,71)$, the changes in the slow luce do correspond to changes in musical texture and tempo, and also frequently align with restatements of important thematic material. Example 14 indicates how the first theme, played by the horns at the opening of the blue-violet Color Stage I, returns near the onset of the central red Color Stage IV, and is sung by the chorus near the beginning of the final blue-violet Color Stage VII. None of the sonata-form readings in Example 13 recognize these reappearances of the first theme as sufficiently "structural" to initiate a new formal section on the large scale. But when paired with a dramatic color shift in the slow luce, these recurrences of the first theme take on a heightened importance. In this way, the slow luce becomes a visual guide to the large-scale divisions of the work, just as the fast luce clarifies the harmonic rhythm.

[50] The structure of the slow luce part itself will still seem arbitrary without knowledge of the work's esoteric program. Publicity surrounding early performances of Prometheus explicitly encouraged audiences to interpret Scriabin's work in light of the theosophical writings of Helena Blavatsky (Sabaneev 2000 [1925], 100; Newmarch 1914). (19) In her magnum opus, The Secret Doctrine (1888), Blavatsky used the Greek myth of Prometheus to illustrate the false duality between good and evil, a cornerstone of theosophical doctrine. Blavatsky associated the semi-divine Titan who was tortured in punishment for bequest of fire to humankind with Jesus, the Christian "Light of the world," a son of God who also suffered for humankind's benefit $(1888$, vol. 1, 468). But even more emphatically, Blavatsky emphasized the parallels between Prometheus and Lucifer, a fallen angel whose Latin name literally means "light-bearer" (ibid., 462n).

[51] The original program for Prometheus printed in the booklet at the 1911 Moscow premiere revealed the work's connection to Blavatsky. The text begins, "Prometheus, Satanas [sic], and Lucifer all meet in ancient myth. They represent the active energy of the universe, its creative principle. The fire is light, life, struggle, increase, abundance, thought" (translated in Bowers 1996, 206-7). This closely paraphrases Blavatsky's description of the Lucifer/Prometheus figure from The Secret Doctrine: "Satan, or Lucifer, represents the active, or . . . the 'Centrifugal Energy of the Universe' in a cosmic sense. He is Fire, Light, Life, Struggle, Effort, Thought, Consciousness, Progress, Civilization, Liberty, Independence” (Blavatsky 1888, vol. 2, 245).

[52] For Blavatsky, Prometheus's theft of fire was an allegory for the acquisition of human intellect, a pivotal moment in the theosophic narrative of human evolution (Blavatsky 1888, vol. 2, 519-28). The Secret Doctrine described how the human soul began as an emanation of the divine spirit, a primal thrill of vibration that Blavatsky conceptualized variously as a breath, a 
sound, and a light. Like a dividing cell, this emanation underwent a process of differentiation over many eons, eventually resulting in a physically embodied being. Although humans had achieved full materialization at the midpoint of the cycle, they still lacked the "sacred spark which burns and expands into the flower of human reason and self-consciousness" (vol. 2, 95). The Promethean enlightenment would eventually allow humans to transcend their base material existence and begin the journey toward divine spiritual reunification.

[53] Example 15a reproduces Blavatsky's diagram of this process (vol. 2, 300). The cycle is divided into seven developmental stages called a "Root Race," loosely based on Hesiod's Five Races (or Ages) of Man. (20) Scriabin was particularly taken by Blavatsky's account of the seven Races, (21) and told Sabaneev that the slow luce in Prometheus delineated the cycle of development described in The Secret Doctrine. "The second line [i.e., the slow luce] corresponds to the whole-tone scale, beginning on $\mathrm{F} \#$ and going by whole steps again to $\mathrm{F} \#$. The second line corresponds to the involution and evolution of the Races. At the beginning is the spiritual, the color blue, then it goes over the other colors to the color red-which is the material, and returns again to blue” (Sabaneev 2000 [1925], 262).

[54] Example 15b shows how Scriabin translated Blavatsky's evolutionary narrative into musical terms. In the slow luce part, Blavatsky's seven-stage cycle of human development became a whole tone cycle, and the metaphysical polarity between spirit and matter became a musical polarity, the tritone between the blue-violet F\# and the red C. Scriabin's designation of blue-violet as "spiritual" and red as "material" was independently corroborated by the psychologist Charles Myers, who wrote, "for [Scriabin] the (red) key of $\mathrm{C}$ relates to matter, and is redolent with the odour of the soil, whereas the (violet) key of F\# is spiritual and ethereal" (Myers 1914-15, 115).

[55] The slow luce and its Blavatskian inspiration invites us to reimagine the way Prometheus engages the basic trajectory of the sonata plot (Example 16). Color Stages I-III portray the material evolution of humanity from a purely spiritual being towards gradual physical embodiment. These color stages introduce the main thematic material of the work, serving an expository function. In the red stage IV, Scriabin represents Blavatsky's period of conflict between the spiritual and material aspects of humanity with fragmented textures reminiscent of a development section and musical tropes of opposition borrowed from the concerto genre. The rare instances of literal repetition in Prometheus mostly fall within the yellow color stage $\mathrm{V}$, indicating its recapitulatory function. (22)

[56] Yet the true visual, thematic, and narrative culmination of the work occurs at the beginning of Color Stage VII, a return to the "spiritual" blue-violet color in the slow luce. Musically, this moment is marked by the triumphant reappearance of the main theme at measure 467, which, significantly, is sung by the chorus (see Example 14). Scriabin, like his Russian mystic Symbolist associates, was fascinated by the theurgic function of the chorus in ancient drama (Schloezer 1987 [1923], 190). (23) The Symbolist poet Viacheslav Ivanov dwelt upon the potential of the chorus to transcend divisions between performers and spectators, transforming theater into ritual. In a 1909 essay he wrote, "the chorus is in and of itself already a symbol, a sensible signification of the concord and unanimity of sobornost, the visible evidence of a real connection that brings isolated consciousness together into a living unity (Ivanov 2001, 33).

[57] At the beginning of Color Stage VII, the chorus in Prometheus sings a single word repeated three times "Eaohoaoho." Scholars have sometimes assumed this text was merely nonsense vocables, or they have tried to relate it to Arthur Rimbaud's symbolist poem "Vowells" (Baker 2002, 69). However, Lobanova (2002, 292-95) identifies Scriabin's "Eaohoaoho," with "Oeaohoo," a mantra invoking "Eternal living Unity" which appears in The Secret Doctrine (Blavatsky 1888, vol. 1, 68). Lobanova's reading underscores the importance of this moment in the narrative and formal logic of the piece, and provides a glimpse into how Scriabin's theosophical and Symbolist sources of inspiration could blend and reinforce each other.

\section{Part IV: The Challenge of Performance}

[58] If the lights perform analytical and interpretative functions, could the staging emphasize this role? In other words, could analysis be performance?

[59] Throughout much of the twentieth century, two problems have plagued lighted productions of Prometheus. First, the 
enigmatic nature of the published light part and the lack of access to information regarding Scriabin's full vision have lent the luce an aura of indeterminacy. In particular, confusion over the function of the slow luce part has sometimes led to a decision to omit it from the performance altogether, $(24)$ to stage it in such a way so that the large-scale changes are obscured, or to freely alter Scriabin's colors. Example 17 summarizes production information for four different lighted performances of Prometheus available on YouTube. (25) The Berlin Philharmonic (1992) and the Latvian National Symphony Orchestra (2003) blended the fast and slow luce parts, making it difficult to tell which part was changing at any given moment. The Tokyo NHK Orchestra (2006) chose to realize only three colors of the slow luce, reducing Scriabin's six stages to just three: blue-violet, red, and yellow. (26) Finally, the Russian National Orchestra (2009) undercut the final climactic return of "spiritual" blue-violet in Color Stage VII by lighting the chorus's entrance with the "material" color of red.

[60] Second, even if realizers do have access to reliable information, Scriabin's indications have always exceeded the capacity of available technology. The failure of the original luce at the 1911 premiere was emblematic of technical difficulties to come. While Mozer's instrument may have inspired awe in a small chamber, it would lose its dramatic impact in a large concert hall unless it was equipped with a projection apparatus. (27) More powerful forms of theatrical lighting were incapable of delivering the precise articulations called for in Scriabin's score. Tungsten lights were coming into widespread use around the time of Prometheus's premiere, and would have had the capacity to light a wider area (Schroeder 1923, 86-89). However, some of Scriabin's rhythms and tempos would have exceeded their response time. Electricity passing through the filament creates both light and heat. The filament dims and cools gradually after the electric current has been turned off. This tiny, yet noticeable fade would blur the articulation of the fast luce at rehearsal 44, where Scriabin's score calls for flashing colors moving with the quarter note pulse of 184 beats per minute.

[61] Interestingly, technological issues would continue to challenge lighted performances of Prometheus for much of the twentieth century. Hugh MacDonald, conductor of several lighted realizations of Prometheus, lamented the work's technical difficulty as late as 1978. "The practical complications are severe. . . a large orchestra and chorus requires a large space in which to be heard, and no method of light-projection yet devised can bathe a large auditorium in colours which may change rapidly, many times in a single bar. ..." (MacDonald 1978, 56).

[62] Many of the notated rhythms in the published score were impossible to realize accurately until the advent of lasers and LEDs. The heightened responsiveness of these technologies allow the lights to be cued almost instantaneously. However, the layer of effects Scriabin added to the Parisian score indicates a level of pyrotechnic spectacle that few productions can accomplish, even today. But even if Scriabin's Parisian annotations can only be partially realized, they offer modern productions an invitation to go beyond the simple idea of music-color correspondence that has become typical of lighted performances of Prometheus. Nearly every bar contains an annotation, each of which falls into one of the following five categories:

1. Color words, often with modifiers indicating subtle changes in hue (Examples: "very red" at measure 153; "soft golden" at measure 215; "bright green" at measure 293).

2. Indications for lighting intensity (Examples: "mysterious semi-darkness" at measure 1; "fades, grows dim" at measures 24-25; a crescendo through measures 140-41 with the word "stronger;" a crescendo through measures 592-93 with the words "becoming glaring, white").

3. Qualities of light (Examples: "translucent" at measure 151; "bright, dazzling" at measure 139; "almost white, sharp" at measure 261; "soft, tender, glittering" at measure 393).

4. Light imagery (Examples: "sparkles, stars, ripple" at measure 157; "several light beams, like on the water" at measure 176; "red flames blazing up," at measure 192; "various sharp-edged shapes" at measure 240; "lighting and cascades of fire like fireworks" at measure 279).

5. Annotations which relate to the ritual or programmatic action (Examples: the piano's final, delirious solo is marked "Dance of flame or amongst the flame" at measure 512; the chorus's triumphant entrance at the beginning of color stage VII is "a whole sea of light and fire" at measure 494; the final measures bear the words "inferno, the whole world engulfed," "cataclysm, all in fire"). 
[63] The Parisian score annotations are traces of an imaginary spectacle, a partial record of Scriabin's irrecoverable vision. His markings still require interpretation and adaptation to the environment in which the performance will take place, just as his musical notation does. Some of Scriabin's markings, especially those in category 5, are unperformable in the literal sense, and can only be evoked rather than realized. Even for productions aiming for fidelity to the notation, there will always be a gap between an ideal Prometheus and an actual performance due to the ever-present limitations of the real world: budget, the availability of technological and artistic resources, load-in and rehearsal time, and so on.

[64] In 2010, the authors of this paper produced a lighted realization of Prometheus in collaboration with the Yale Symphony Orchestra, conducted by Toshiyuki Shimada, with pianist Daniel Schlosberg. (28) Our goal was to follow Scriabin's 1911 published notation for luce and his 1913 Parisian score annotations within the practical limitations of our production circumstances. We were particularly interested in exploring ways to stage the lights that emphasized their interpretative function. To review, lights and music interact in six ways: 1) the fast luce articulates the harmonic rhythm; 2) the slow luce articulates the form, and segments the piece into episodes relating to the work's program; 3) the lights help shape musical phrases through dynamics; 4) interaction between light parts connect temporally-distant moments through foreshadowing and reminiscence; 5) special effects support the programmatic narrative; and 6) color symbolism supports the programmatic narrative.

\section{Staging the fast and slow llumce parts}

[65] Our performance space, Woolsey Hall, was completed in 1901, ten years before the Moscow premiere of Prometheus. We projected lights onto the hall's interior structures, taking inspiration from the way Scriabin imagined lights and architecture would interact in his Mysterium. Scriabin told the pianist Anna Goldenweiser that "the form of the cathedral . . will continually change, along with the atmosphere and motion of the Mysterium. This, of course, [will happen] with the aid of mists and lights, which will modify the architectural contours"' (quoted in Morrison 2002, 194).

[66] In order to capture the bi-level temporal hierarchy and separate musical functions of the fast and slow luce parts, we divided them spatially in the hall (Example 18). While lights on Woolsey Hall's ceilings and columns articulated the large-scale color changes of the slow luce, a smaller lighting installation upstage performed the faster-moving colors in time with the harmonic rhythm. (29)

[67] The fast-luce installation was comprised of twelve versa tubes arranged as a starburst. Its circular design was an homage to Mozer's 1910 instrument. As described in Part II above, we believed Mozer's luce provided a visual display of mystic chord root motions on the circle of fifths. We hoped our instrument would be capable of translating the musical symmetries of Scriabin's fundamental bass patterns into symmetrical divisions of the wheel. But cueing the versa tubes individually did not provide the dramatic impact that we required in a large hall. (30) Instead, we used all twelve tubes as a solid color field, allowing us to demarcate the harmonic rhythm with greater dynamism. We added a series of effects, allowing the performer to change colors, intensity, and quality in real time.

[68] Video 2 illustrates our staging of the fast and slow luce parts. The clip begins with the piano's solo at the end of Color Stage I, marked très animé, étincelant (Score Excerpt 1). The passage begins with the fast luce installation moving in rhythm with the quarter-note beat. The deep blue-violet of the orchestra hall corresponds to the F\# of Color Stage I, but at Rehearsal 4 (timepoint 0:25) the hall changes to "lily-color" (fuchsia), the color of Stage II (Ab) aligned with a change of mood and a new theme in the piano marked voluptueux, presque avec douleur.

\section{Dynamic shaping}

[69] Historically, the legend of Scriabin's synesthesia has focused attention solely on relationships between pitch and color in Prometheus, giving rise to performances that present the luce as merely a play of shifting hues. (31) But the idea that the luce's expressivity is due to color alone is analogous to the idea that the orchestra's expressivity is due to pitch alone. In both, changes in dynamics, texture, and articulation underscore the work's dramatic and emotive content. 
[70] Score Excerpt 2 shows a passage from the grey Color Stage III. At R9, the piano recapitulates the head motive from the main theme of the work (thème large majesteux). The piano enters on a yellow D mystic chord, accompanied by the annotation "regal, yellow, bright." The piano's solo triggers an orchestral entrance on blue-violet F\# mystic chord at R10 (enthousiame). As Scriabin's Parisian score markings indicate, the ensuing orchestral climax is the brightest point in the piece yet: "light intensifies, nearly white, glaring; bright, dazzling."

[71] The lush texture and lyrical momentum is interrupted at R11 by syncopated quarter notes in the harp (limpide), followed by a tympani hit and an ascending fourth in the trumpet (sourd, menaçant). In the Parisian score, Scriabin annotated the limpide — sourd, menaçant figure as "pale, reddish; watery, trembling; immediately dark." In Video 3, the lighting intensity parallels the music's dynamic shape, building slowly with the piano's solo, climaxing with the orchestral entrance, and suddenly dimming with the limpide—sourd, menaçant interruption.

\section{Color foreshadowing and reminiscence}

[72] Color, often supported by lighting quality and dynamics, helps underscore long-range connections between specific moments in the work. Similar to associative tonality in Wagner, the quickly changing colors of the fast luce (corresponding to a mystic-chord "tonality") can foreshadow or recall colors of the slow luce and their corresponding formal sections. These

"light motives" support processes of foreshadowing and recollection occurring in the musical domain, creating a multisensory network of relations.

[73] The limpide — sourd menaçant figure at R11 is a particularly clear example of this technique (Score Excerpt 2). Its contrasting color, dynamics, texture, and gesture mark it as an anomaly in its immediate musical context. This figure foreshadows the onset of the red Color Stage IV nearly 40 measures later, which begins with identical music and color (Score Excerpt 3). In our production, we highlighted this relationship by setting each passage with identical lighting dynamics, according to Scriabin's Parisian score annotations (compare Video 3, timepoint 0:41 to Video 4).

[74] The complete passage from R9-12 embeds more subtle long-range connections. Musically, the piano's solo at R9 connects to other appearances of the main theme elsewhere in the work. The piano's solo in Color Stage III was prepared by a short statement in the solo violin beginning at R8+5 (Score Excerpt 2); this statement returns in Color Stage VI, R32-2 (Score Excerpt 4), but this time followed by a single head motive of the main theme in the solo violin. Reorchestration and abbreviation slightly obscures the musical relationship between these two moments, but the piano's entrance on a yellow D mystic chord in the earlier passage (marked "regal, yellow, bright") helps connect it to the violin solo in the later yellow Color Stage (compare Video 3 to Video 5).

\section{Special effects and Color Symbolism}

[75] We integrated many of the large-scale dynamic changes and special effects with the colors of the slow luce part. Video 6 shows the orchestral climax at the end of Color Stage IV. Scriabin's annotations for this passage in the Parisian score are filled with fire imagery, such as "flame kindles and grows brighter," "flares and splinters of flame," and "blazing stronger." In this passage, flame effects and the hellish red color set the hall ablaze.

[76] As described in part III, the slow luce's progression from blue-violet to red and back symbolized the evolution of souls between spirit and material states in the work's programmatic narrative. Video 7 shows Color Stage VI (E, blue-greenish) and the transition to Color Stage VII (F\#, blue-violet). The passage begins with a crazed dance for piano, which Scriabin described as "in a vertigo, dance of flames or amid the flames" in the Parisian score. Despite the blue-green color of the section, we used flame effects to create a visual parallel between the piano's Color Stage VI dance and the flames that brought the red Color Stage IV to a close (Video 6).

[77] The piano's dance triggers two choral entrances, one at the end of Color Stage VI and one initiating Color Stage VII. The first of these occurs in Video 7, timepoint 0:52. Significantly, the chorus enters on a Gb mystic chord, enharmonically equivalent to F\#. Here, the harmony and the fast luce color foreshadow the blue-violet of the final stage, which arrives at 
timepoint 1:04. The chorus enters again, singing a mantra from The Secret Doctrine set to the main theme.

[78] Schloezer (1987 [1923], 267-68) describes how Scriabin hoped to create ritualized performances that would annihilate barriers between performers and spectators. Scriabin's views were likely informed by his encounter with Symbolist theories of the theater as well as his reading of Nietzsche's Birth of Tragedy. Nietzsche had theorized that the chorus in ancient Greek drama mediated between actors and audience, occupying the interstitial space and performing dual roles as observer and participant in the drama (Nietzsche 2000, 62-64). In our staging, we seated the choral members in the audience. When they rose for their first entrance, they enacted the transformation from observer to participant.

\section{Part V. Conclusion}

[79] So, do the lights matter? Do Scriabin's colors and rhythms matter? There is long tradition of a performance, critical reception, and scholarship that assumes the answer is no. Clarence Lucas set the tone in his 1915 review of the New York lighted premiere. He wrote that the lights had "no possible connection to the music," and "served to divert the senses of the audience from a too concentrated attention on the music" (quoted in Hull 1927, 227). These sentiments would be repeated by reviewers in the decades to come, and even resurface in modern scholarship. Cook, writing in 1998, claimed that "the luce part literally does add little; for while the slower part has no discernible relationship to what is heard, the faster part simply duplicates information that is already present in the music." Citing the lack of perceptual interaction between what is seen and heard, Cook concluded, "in a significant sense, Prometheus does not belong to the history of multimedia at all" (1998, 38).

[80] If Prometheus is a multimedia failure, it is well worth asking where the failure lies: in conception, production, or audience reception. Too often, critics have blamed Scriabin for the faults they perceive in the work. (32) But is this really fair, considering that for such a long time we had little idea of what that conception actually entailed, and inadequate technological means to realize it?

[81] There is an additional factor to be considered concerning Prometheus's failure. When Prometheus is performed with lights, it is usually in a concert hall, a space normally reserved for reverent appreciation of the "music itself." Listeners who are deeply enculturated in traditional modes of classical music listening and who are invested in the idea of musical autonomy want their experience of the music disturbed as little as possible. These listeners tend to be highly educated, and are usually the ones granted authority to review concerts. Lucas revealed his own bias against any form of musical multimedia in his 1915 review: "Scriabin, therefore, succeeded in making his music heard in exactly the same way that operatic music in general is heard-that is, with a divided attention." Traces of this attitude continue to resurface in reviews today. Shows involving a high degree of spectacle risk the charge of tackiness or distraction, whereas ones with more subtle lighting effects are praised because they allow critics to sit back and focus on the music. (33)

[82] If, as we argue, the lights and music are equal components of the whole, then focusing on the music is perhaps not the most appropriate way to listen to Prometheus. If audience members have the ability to sit back and listen to Prometheus the way they would to any other symphony concert, the lights simply aren't doing their job. Indeed, what we know about Scriabin is that he wanted his music to disturb, and to do so beyond the usual riot-at-the-theater that greeted other early modernist works. Scriabin wanted his music to disturb on a cosmic, metaphysical, and molecular level.

[83] In "Skryabin and the Impossible" (1998), Simon Morrison describes just how seriously the composer took the Russian Mystic Symbolist's call for a new art that would transfigure reality. Scriabin conceived of his Mysterium as an impossible, ritualized Gesamtkunstwerk that would trigger apocalypse through the use of a mythic symbolist libretto, multi-sensory stimulation, and new tonal combinations. Prometheus's reference to myth, its meticulous coordination of sound and color, and famous non-triadic harmonic structures encourage us to view it as a proto-Mysterial experiment, a preliminary etude for the ultimate work that would bring about the dematerialization of the world and universal spiritual reunification. Scriabin's annotations in the Parisian score reveal just how conceptually close Prometheus was to the Mysterium. In Prometheus, Scriabin's final indications read, "inferno, the whole world engulfed," "cataclysm, all in fire" (1911/1913, 79). Like the Mysterium, Prometheus was to be no mere sound and light show, but rather something else entirely—a work of art that would change the world as we know it. 
[84] Scriabin's apocalyptic preoccupations provide insight into why he would want to combine sound and light in the first place. In The Secret Doctrine, Blavatsky described the universe as permeated by a powerful energy called $A k \hat{a} a$, a unitary vibration possessing multisensory properties: "Sound is the characteristic of $A$ kasa (Ether): it generates air, the property of which is Touch; which (by friction) becomes productive of Colour and Light" (1888, vol. 1, 205). According to The Secret Doctrine, tapping into Akâsa could produce tremendous effects in the real world (511-12). Speaking for Scriabin, Boris de Scholezer, the composer's brother in law, explained the composer's belief in the power of mystic vibration:

There is no doubt that if we could make visible all vibrations of the air mass produced in the vicinity . . of a performance of Scriabin's Prometheus — we would find that all objects, including our own bodies, vibrate in such complex rhythms as to induce the disintegration and transformation of matter (Schloezer 1987 [1923], 240-41).

[85] By combining sound and light in Prometheus, Scriabin could harness Akâsa, transforming a programmatic tone poem into an artwork that had real spiritual power. (34) In other words, Scriabin hoped Prometheus would become an agent in the very metaphysical narrative it recounted, exemplifying the symbolist's belief in the power of art to transform reality.

[86] So, no matter how well-researched and realized, every production of Prometheus will fail to completely fulfill what we know about the composer's intentions. But if Prometheus is doomed to fail given one set of mystic symbolist aspirations, it can succeed according to another. Scriabin's friend, the poet Viacheslav Ivanov, described symbolism as "an art that turns the perceiver into a participant in the creative act"; true artworks arise from a mutual collaboration between an artist and audience (Ivanov 2001, 51). In Prometheus, Scriabin's generations of realizers can become his ideal receivers, collaborating with him across the decades to produce more and more spectacular versions of his impossible work. Prometheus embeds a particularly modernist paradox: it was a vision of the future, so only in the future can an "authentic" production be realized-a statement perhaps as true today as it was a century ago.

\section{Anna M. Gawboy \\ The Ohio State University School of Music \\ 110 Weigel Hall \\ 1866 College Road \\ Columbus, OH 43210-1170 \\ Gawboy.2@osu.edu}

Justin Townsend

Northeastern University

Theatre Department

193 Ryder Northeastern University

Boston MA 02115

J.townsend@neu.edu

\section{Works Cited}

Baker, James. 2002. "Prometheus and the Quest for Color-Music: The World Premiere of Scriabin's Poem of Fire with Lights, New York, March 20, 1915.” In Music and Modern Art, edited by James Leggio, 61-95. New York: Routledge.

1986. The Music of Alexander Scriabin. New Haven: Yale University Press.

Bazayev, Inessa. 2009. "Composing with Circles, Spirals, and Lines of Fifths: Harmony and Voiceleading in the Works of Nicolai Roslavets.” PhD diss., City University of New York. 
Blavatsky, Helena. 1888. The Secret Doctrine: The Synthesis of Science, Religion, and Philosophy. Two volumes. London: The Theosophical Publishing Company.

Bowers, Faubion. 1996. Scriabin: A Biography. New York: Dover.

Cheong, Wai-Ling. 1990. “The Late Scriabin: Pitch Organization and Form in the Works of 1910-14.” PhD diss., University of Cambridge.

- 1993. "Orthography in Scriabin's Late Works.” Music Analysis 12, no. 1: 47-69.

1996. “Scriabin's Octatonic Sonata." Journal of the Royal Musical Association 121, no. 2: 206-28.

Cook, Nicholas. 1998. Analysing Musical Multimedia. Oxford: Oxford University Press.

Cytowic, R. 2002. Synesthesia: A Union of the Senses. Second edition. Cambridge: MIT Press.

Dann, Kevin T. 1998. Bright Colors Falsely Seen: Synaesthesia and the Search for Transcendental Knowledge. New Haven: Yale University Press.

Delson, Viktor. 1971. Skryabin: osherki zhizni i tvorchestva [Skryabin: essays on his life and works]. Moscow.

Dillon, Christopher. 2002. "Scriabin's Synaesthesia and its Significance in Prometheus, Poem of Fire, Op. 60, and in Other Selected Late Works.” DMA document, Peabody Conservatory of Music.

Dimova, Polina. 2009. “The Poet of Fire: Aleskandr Skriabin's Synaesthetic Symphony 'Prometheus' and the Russian Symbolist Poetics of Light." Institute of Slavic, East European, and Eurasian Studies, UC Berkeley. http://escholarship.org/uc/item/25b624gd\#page-1

Eberle, Gottfried. 1978. Zwischen Tonalität und Atonalität: Studien zur Harmonik. Alexander Skrjabins. Salzburg: Katzbichler.

Fields, William. 1969. “Symphony Concert 'Remarkable.”' Yale Daily News. November 25.

Galeev, Bulat M. and Irina L. Vanechkina. 2001. "Was Scriabin a Synesthete?” Leonardo 34, no. 4: 357-61.

2010. Poema ognia: konseptsiia svetomusykal'nogo sinteza A. N. Skriabina [Poem of fire: A. N. Skryabin's concept of light-music synthesis]. Kazan: Kazanskaia gosudarstvennaia Konservatoriia.

Gleich, Clement-Christoph von. 1963. Die Sinfonischen Werke von Alexander Skrjabin. Biltoven: A. B. Creyghton.

Horst-Lederer, J. 1980. "Die Funktion der Luce-Stimme in Skrjabins op. 60." In Alexander Skrjabin, edited by Otto Kolleritsch, 128-41. Graz: Universal Edition.

Hull, Arthur Eaglefield. 1927. A Great Russian Tone Poet: Scriabin. 2nd ed. London: Trübner and Co., Ltd.

Ivanov, Viacheslav. 2001. Selected Essays. Translated by Robert Bird. Evanston: Northwestern University Press. 1909. Po zvedzdam [By the Stars]. St. Petersburg: Ory.

Kallis, Vasilis. 2008. "Principles of Pitch Organization in Scriabin's Early Post-tonal Period: The Piano Miniatures." Music Theory Online 14, no. 3. http://www.mtosmt.org/issues/mto.08.14.3/mto.08.14.3.kallis.html

Krumhansl, C. L., G. J. Sandell, and D. C. Sergeant. 1987. "The Perception of Tone Hierarchies and Mirror Forms in Twelve-Tone Serial Music." Music Perception 5, no. 1: 31-78.

Lerdahl, Fred. 1988. "Cognitive Constraints on Compositional Systems.” In Generative Processes in Music, edited by J. Sloboda. 
Oxford: Oxford University Press, 231-59.

2004. Tonal Pitch Space. Oxford: Oxford University Press.

Lobanova, Maria. 2002. “Zahlen, Mystik, Magie: Neueste Erkentnisse zu Skrjabins Prométhée.” Das Orchester 50, no. 1: 7-8. 2004. Mystiker, Magier, Theosoph, Theurg: Alexander Scriabin und seine Zeit. Hamburg: Bockel Verlag, 2004.

Macdonald, Hugh. 1978. Skryabin. Oxford: Oxford University Press.

1983. "Lighting the Fire: Skryabin and Color." The Musical Times 124, no. 1688: 600-602.

Morrison, Simon. 1998. "Skryabin and the Impossible." Journal of the American Musicological Society 51, no. 2: $283-330$.

2002. Russian Opera and the Symbolist Movement. Berkeley and Los Angeles: University of California Press.

Myers, Charles. 1914-15. “Two Cases of Synaesthesia.” British Journal of Psychology 7: 112-17.

Newmarch, Rosa. 1914. “Prometheus': The Poem of Fire.” The Musical Times 55, no. 854, 227-231.

Nietzsche, Friedrich. 2000. The Birth of Tragedy. In Basic Writings of Nietzsche, translated by William Kaufman, 1-144. New York: Modern Library.

Perle, George. 1984. “Scriabin’s Self-Analyses.” Music Analysis 3, no. 2: 101-22.

Plummer, Harry. 1915. "Color Music_-A New Art Created With the Aid of Science.” Scientific American 112: 343, 350-51.

Pople, Anthony. 1989. Skryabin and Stravinsky 1908-1914: Studies in Theory and Analysis. New York and London: Garland.

Reise, Jay. 1983. “Late Skriabin: Some Principles Behind the Style.” Nineteenth Century Music 6, no. 3: 220-31.

Sabaneev, Leonid. 1910. “Prometei.” Muzyka 1 (November 27): 6-11.

. 1911a. "O zvuko-tsvetovom sootvetstyi” [On sound-color correspondence]. Musyka 9 (January 29): 196-200.

. 1911b. "Prometei Skriabina." Musyka 13 (February 26): 287-95.

1929. "The Relation Between Sound and Color." Translated by S. W. Pring, Music and Letters 10, no. 3: $266-67$.

1974 [1912]. "Scriabin's Prometheus." In The Blaue Reiter Almanac, edited by Wassily Kandinsky and Franz

Marc, translated by Henning Falkenstein, 127-44. London: Thames and Hudson.

- 2000 [1925]. Vospominanïa o Skriabine [Reminiscences of Skryabin]. Moscow: Klassika-XXI.

2000-01 [1910]. "Prometheus-A Preview." Translated by Don Luis Wetzel. Journal of the Scriabin Society of America 5, no. 1: 97-105.

Sabbagh, Peter. 2001. The development of harmony in Scriabin's works. Boca Raton: Universal Publishers.

Schloezer, Boris. 1987 [1923]. Scriabin: Artist and Mystic. Translated by Nicolas Slonimsky. Berkeley: University of California Press.

Schroeder, Henry. 1923. History of Electric Light. Washington: Smithsonian Institution.

Scriabin, Alexander. 1911/1913. Autograph score of Prométhée, le Poème du Feu, pour grand orchestre et piano avec orgue, choeurs, et clavier à lumièrs, op. 60. Berlin and Moscow: Edition Russe de Musique. 
. n.d. [ca. 1980]. Prométhée, le poème du feu Op. 60. London: Editions Eulenburg.

1965. Pis'ma [Letters]. Edited by Alexi V. Kashperov. Moscow: Muzyka.

1995. "Poem of Ecstasy" and "Prometheus: Poem of Fire" in Full Score. Mineola: Dover.

Taruskin, Richard. 1988. Reviews of "The Music of Alexander Scriabin" by James M. Baker and "Scriabin: Artist and Mystic" by Boris de Schloezer. Music Theory Spectrum 10, no. 1: 143-69.

1997. "Scriabin and the Superhuman: A Millennial Essay." In Defining Russia Musically: Historical and Hermeneutical Essays, 308-59. Princeton: Princeton University Press.

2005. The Oxford History of Western Music. Vol. 4. Oxford: Oxford University Press.

Tommasini, Anthony. 2011. "The Colors and Sounds of Scriabin.” New York. Times, November 4. http://www.nytimes.com /2011/11/05/arts/music/spectral-scriabin-at-baryshnikov-arts-center-review.html, accessed 2/13/12.

Tymoczko, Dmitri. 2011. A Geometry of Music: Harmony and Counterpoint in the Extended Common Practice. Oxford: Oxford University Press.

Vanechkina, Irina. 1975. “O tsvetnom slukhe A. N. Skriabina [“On Scriabin's Colored Hearing”].” In Materialy Tret' $\breve{e}$ konferentsii Svet i musyka, 31-33. Kazan, Russia: KAI.

- 2012 [1977]. “The 'Luce' part as a clue to Scriabin's later harmony.” http://prometheus.kai.ru/luce_e.htm, accessed 2/13/12. Translated by Vanechkina from her article in Sovietskaya musyka 4, 100-103.

. 2012 [2000]. "On the Parisian score of Prometheus." http://prometheus.kai.ru/parisian_e.htm, accessed 2/13/12. Translated by Vanechkina from her article in Materialy Tret’ĕ konferentsii Prometĕ 2000, 51-54. Kazan, Russia: FEN.

- 2012. "On the Performances of A. Scriabin's 'Lighting Symphony': Myths and Reality." http://prometheus.kai.ru/perform_e.htm, accessed 2/13/12.

\section{Footnotes}

*. Shorter versions of this article were presented at Music Theory Midwest in Oxford Ohio (2010) and the Society for Music Theory Annual Meeting in Indianapolis, Indiana (2010). The authors wish to thank Seth Monahan, Kathryn Graber, and two anonymous reviewers for their helpful comments and suggestions regarding earlier drafts.

Return to text

1. For example, Jennifer Tipton, the designer of a 2010 lighted piano recital of Scriabin's music entitled "Spectral Scriabin," made a point to distance her work from Scriabin's vision: http://www.theworld.org/2010/10/alexander-scriabin/. And although the kinetic artist Norman Perryman claimed to be channeling various Scriabinesque ideas as he painted during a 2010 performance of the Poem of Ecstasy, his performance only loosely engaged Scriabin's ideas regarding color and music. (See the YouTube performance here.) Scriabin did not include a multimedia component in the piano music or the Poem of Ecstasy, so there are no explicit directions for designers to either follow or reject. But designers take similar liberties with Prometheus, which did include a part for colored lights; see section IV.

Return to text

2. A selection of these sources includes Sabaneev 1974 [1912], 1911a, 1911b, 1929; and Myers 1914-15.

Return to text

3. Performative impossibility as an aesthetic value in Scriabin's music has been explored by Taruskin (1997), and Morrison 
(1998 and 2002).

Return to text

4. A brief history of lighted performances of Prometheus can be found in Galeev and Vanechkina 2010, and Vanechkina 2012. Return to text

5. Scriabin 1911/1913, archived under the Bibliothèque Nationale catalogue number Res. Vma 228. The score has been described by a number of scholars, including Lobanova (2004), Dillon (2002), Vanechkina (2012 [2000]), MacDonald (1983), Horst-Lederer (1980).

Return to text

6. For example, as of $11 / 1 / 11$, the Wikipedia entry on "clavier à lumières" contained numerous inaccuracies and contradictions (http://en.wikipedia.org/wiki/Tastiera_per_luce). It stated that a table correlating pitch and color according to Scriabin's "synesthetic system" "appears in the [published] score." Scriabin was not a synesthete as we have come to define the term today, and no such table appeared in the first edition score. Wikipedia then provides a list of colors mapped to pitch classes arranged as an ascending chromatic scale. Not only does a chromatic arrangement represent a fundamental misunderstanding of the premise behind Scriabin's system, but some of Wikipedia's tone-color assignments differ significantly from those appearing in the Parisian score manuscript. Wikipedia also states, “the 'luce' part is notated ... [as] two parts, one proceeding on the circle of fifths and the other following the tonal centre of the music." Neither statement is accurate.

Return to text

7. Baker 2002, 73-78; Galeev and Vanechkina 2001, 357-61; and Dillon 2002, 2-25.

Return to text

8. When the notation is realized, the lights project colors corresponding to the notated pitches, not sounds.

Return to text

9. The orthography of Example 5 follows that of Sabaneev 1911b, 289. This article and its famous presentation of the mystic collection as stacked fourths became available to western analysts in Sabaneev 1974 [1912]. Scriabin's sketches for Prometheus reveal that he experimented with mystic chord arrangements in stacked thirds and stacked fourths. In both, the fundamental of the collection remains the same. See Lobanova 2002, 7-8 and Eberle 1978, 64.

Return to text

10. Sabaneev revealed the relationship between the fast luce harmonies and the mystic chord fundamental in his memoir. Scriabin explained, "it is but very simple. You see, I have two lines of color flowing throughout the whole Poem. The first [faster-moving line] corresponds to the music, the harmonies, and therefore often the fundamental bass" (Sabaneev 2000 [1925], 262). This relationship has long been acknowledged by scholars, including Gleich (1963), Vanechkina (2012 [1977]), Eberle (1978), Pople (1989), Sabbagh (2001), and Lobanova (2002). Dillon (2002, 29-74) explores this relationship in great detail. His mystic-chord analysis of the entire composition confirms that the fast luce part matches the fundamental bass of the mystic chords with few exceptions, and nearly all those exceptions could be interpreted as errors.

Return to text

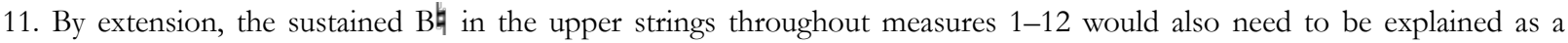
non-collectional tone.

Return to text

12. Perle $(1984,109-110 ; 117-18)$ argued for 8-28, then for 9-10; Pople (1989, 133-36) carefully considered both 9-10 and 10-4 before coming down in favor of 9-10; Cheong (1990, 125-39) swept all three aside to claim 9-12 as the basis for op. 67 no.1; Lehrdahl (2004, 321-33) concluded that op. 67 no. 1 was "essentially octatonic with whole-tone and mystic offshoots"; Kallis $(2008,1.8$; 3.16-17) summarizes the merits of previous arguments before supporting a 9-10 interpretation.

Return to text 
13. Perle (1984) and Cheong (1993 and 1996) have established the importance of orthography in Scriabin's music.

Return to text

14. This has not necessarily inhibited an actual understanding of the relationship between the fast luce part and the harmonies. In his set-theory analysis of Prometheus, Baker wrote, "an element of each 6-34 is nearly always represented in the color organ. This pitch class is almost invariably the third element in the normal-order form." Although Baker insisted that "we need not accept superposed fourths as the basic form of the chord," he acknowledged that fourth-stacking resulted in a correlation between mystic chord root and the pitches of the slow luce (Baker 1986, 258-59).

Return to text

15. Scriabin's compositional protégé, Nicolai Roslavets, used a similar approach to tonal organization. Bazayev (2009) investigates how Roslavets generated arrays of orthographically-distinctive pitches by transposing his synthetic scales through a fifth-series.

Return to text

16. Lerhdahl (1988) identifies a gap between what he calls compositional grammar and listening grammar in serialism. See also empirical study by Krumhansl, Sandell, and Sergeant (1987). Tymoczko (2011, 24-25) presents some similar arguments regarding tonal music.

Return to text

17. Other colors interrupt the whole-tone progression of the slow luce part in several places. The sustained $\mathrm{Bb}$ (metallic leaden grey) gives way to B 305-9 of Db (violet), F (dark red) and A (grass green) separates the slow luce progression from C to D. Finally, the printed score contains an E\# in bar 469, chromatically passing between E (blue-green) and F\# (dark blue-violet); however, Scriabin crossed this E\# out in the Parisian score. Scholars have advanced various explanations for these breaks; see Pople 1989, 244-47 and Dillon 2002, 60-74.

Return to text

18. Pople (1989, 234-43) identifies only four passages of literal repetition: i) measures 26-46; ii) measures 67-82; iii) measures 115-30; and iv) measures 130-45. In the latter half of the piece, the third segment (iii) returns first at measures 309-24, followed by segment (i) at 370-90, then (ii) and (iv) at measures 391-406 and 467-507 respectively. The longest of these sections is only twenty measures, a relatively small proportion of a composition over six hundred measures long.

Return to text

19. Scriabin's interest in Blavatsky's writings and other theosophical sources is well-documented. In a letter to his common-law wife Tatiana Schloezer dated April 29, 1905, Scriabin wrote, “The Key to Theosophy [by Helena Blavatsky] is a wonderful book. You will be amazed how close it is to my thought” (Scriabin 1965, 369). Scriabin's brother-in-law, Boris de Schloezer, described how avidly Scriabin read Blavatsky's The Secret Doctrine, marking significant passages in pencil (1987 [1923], 72).

Return to text

20. Like Hesiod, Blavatsky believed the modern human "race" had reached the fifth stage of development, and she predicted two future stages. In this context, "race" refers not to ethnic/cultural/physiognomic difference but rather a class of (mythic) being. For example, Blavatsky's Root Race I consisted of disembodied and mindless spiritual shadows, while Root Race III was comprised of giants, human-animal hybrids, and divine hermaphrodites.

Return to text

21. When Boris de Schloezer visited Scriabin in Switzerland in 1907, he found the composer "deeply engaged in reading works by Mme. Blavatsky, Annie Besant, C. W. Leadbeater, and other theosophists. His conversation was full of theosophical allusions to Manvantara, Pralaya, Seven Planes, Seven Races, and the like; he used these terms volubly as if they were familiar to all and as if they reflected incontrovertible truths" (Schloezer 1987 [1923], 67). 
Return to text

22. The yellow Color Stage V begins in measures 309-24 with the rapture episode drawn from measures 115-30. Measures 325-40 contain a varied orchestral rendition of the piano's solo from measures 131-38. In measures 370-90, Scriabin brings back the opening dialogue between piano and orchestra from measures 27-47, and then reprises the "trés anime" episode from measures 67-80 in measures 391-404.

Return to text

23. Scriabin's engagement with the mystic phase of Russian Symbolism dates from at least 1909. During the composition of Prometheus, Scriabin read essays by Viacheslav Ivanov collected in By the Stars (Ivanov 1909). Ivanov's essays "Presentiments and Portents: The New Organic Era and the Theater of the Future" and "Wagner and the Dionysian Rite" help contextualize aspects of Scriabin's creative ambitions. See Morrison 1998.

Return to text

24. MacDonald (1978) describes two performances that omitted the slow luce: one by the Dutch Residentie Orkest, conducted by Michael Gielen on March 24, 1973; another by the Oxford University Orchestra, conducted by MacDonald himself on June 22, 1979.

Return to text

25. Of course, no visual recording could possibly capture a viewer's experience of a live performance. In a live performance, the viewer has the freedom to choose what he or she looks at in real time. In a visual recording the editor has already made many of these decisions. In each of the recordings discussed, the visual continuity of the light part is broken by cuts to performer close-ups.

Return to text

26. While they did not fully realize the colors of the luce, the producers of the Tokyo NHK Orchestra did have access to the Parisian score, and their effects are quite spectacular.

Return to text

27. The first public lighted performance of Prometheus used a projection machine designed by Edison Testing Laboratories. Lights were mounted on a rotating belt equipped with mirrors which enabled the colors to be projected onto layers of gauze sheets hung behind the orchestra (Plummer 1915, Baker 2002). This innovation still restricted the lights to a relatively small area upstage, falling short of Scriabin's desire to fill the hall with fire. Even today, some modern productions project lights on a screen, drawing upon this relatively inexpensive and practical precedent.

Return to text

28. The full performance may be viewed on YouTube: http://www.youtube.com/watch?v=V3B7uQ5K0IU.

Return to text

29. Both fast and slow luce parts were performed by musicians during the show. For the slow luce, we pre-wrote cues controlled by a light board. The fast luce installation was connected to a midi keyboard played by a musician who sat among other members of the orchestra.

Return to text

30. Our experience with our luce thus somewhat paralleled Scriabin's own. The instrument did not perform according to our imagined ideal, and so we had to modify our plan to fit our circumstances. Such an experience is intrinsic to the act of performance, and, we might argue, central to the creative aesthetics of Prometheus itself.

Return to text

31. A performance by the Berlin Philharmonic (1992) belongs to this tradition. Some brightening and dimming occurred as the lights shifted from one area of the concert hall to the next, but in general, dynamics and effects were minimal.

Return to text 
32. For example, Fields (1969) wrote, "I must confess that I could see little connection between the lights and the music. It was fun to watch the lights blink on and off, but the intended higher level of experience escaped me. The fault, of course, may lie more in Scriabin's conception than in this or any execution of the work. It was difficult, moreover, to focus attention on the orchestra's contribution, for the novelty of the light show distracted from the music."

Return to text

33. For example, in a 2011 New York Times review of "Spectral Scriabin," a lighted piano recital, Anthony Tomassini wrote, "Ms. Tipton's designs here were fairly tame . . f for most of the performance the lighting effects were quite simple: circles of pale, overlapping colors projected on a screen behind the pianist and on the floor around the piano. Maybe Ms. Tipton knew what she was up to. Without too much intrusion from lighting designs, the focus remained on the music" (Tommasini 2011).

Return to text

34. Blavatsky described Akâsa and related forces as a kind of "Life-Electricity" (1888, vol. 1, 15; vol. 2, 250), endowing the current running through Scriabin's luce with an extra layer of mystical significance. Dimova (2009) investigates the way Scriabin's use of electricity may have resonated with metaphors of light and energy in Symbolist literature.

Return to text

\section{Copyright Statement}

\section{Copyright (C) 2012 by the Society for Music Theory. All rights reserved.}

[1] Copyrights for individual items published in Music Theory Online (MTO) are held by their authors. Items appearing in MTO may be saved and stored in electronic or paper form, and may be shared among individuals for purposes of scholarly research or discussion, but may not be republished in any form, electronic or print, without prior, written permission from the author(s), and advance notification of the editors of MTO.

[2] Any redistributed form of items published in $M T O$ must include the following information in a form appropriate to the medium in which the items are to appear:

This item appeared in Music Theory Online in [VOLUME \#, ISSUE \#] on [DAY/MONTH/YEAR]. It was authored by [FULL NAME, EMAIL ADDRESS], with whose written permission it is reprinted here.

[3] Libraries may archive issues of $M T O$ in electronic or paper form for public access so long as each issue is stored in its entirety, and no access fee is charged. Exceptions to these requirements must be approved in writing by the editors of $M T O$, who will act in accordance with the decisions of the Society for Music Theory.

This document and all portions thereof are protected by U.S. and international copyright laws. Material contained herein may be copied and/or distributed for research purposes only.

Prepared by Michael McClimon, Editorial Assistant 